\title{
Thermal stability of some naphthalene- and phenyl-based epoxy resins
}

\author{
Yeh-Fang Duann ${ }^{\mathrm{a}, *}$, Tsan-Min Liu ${ }^{\mathrm{a}}$, Kuo-Chung Cheng ${ }^{\mathrm{a}}$, W.-F. Su ${ }^{\mathrm{b}, \mathrm{c}}$ \\ ${ }^{a}$ Department of Chemical Engineering, National Taipei University of Technology, 1, Sec. 3, \\ Chung-Hsiao E. Rd. Taipei 106, Taiwan \\ ${ }^{\mathrm{b}}$ Department of Materials Science and Engineering, National Taiwan University, Taipei, Taiwan \\ ${ }^{\mathrm{c}}$ Institute of Polymer Science and Engineering, National Taiwan University, Taipei, Taiwan
}

Received 27 October 2003; received in revised form 15 December 2003; accepted 3 January 2004

Dedicated to Professor Kwan-Ting Liu on the occasion of his 65th birthday.

\begin{abstract}
Six epoxy monomers were synthesized and cured using 4,4 $4^{\prime}$-methylenedianiline (DDM). The glass transition temperatures $\left(T_{\mathrm{g}}\right)$ of naphthalene- and phenyl-based epoxy resins were in the ranges $175-213{ }^{\circ} \mathrm{C}$ and $128-200{ }^{\circ} \mathrm{C}$, respectively. Naphthalene-based epoxy resins 1,5-bis(2,3-epoxypropoxy)naphthalene (A) and 2,7-bis(2,3-epoxypropoxy)naphthalene (B) have almost equal LOIs, implying that the effects of the position of the substituent on LOI was very weak. 4,4' -Bis(2,3-epoxypropoxy)benzylideneaniline (D) has the lowest LOI. The same trend was exhibited when some of the epoxy monomers were cured using the curing agent, sulfanilamide (SAA). The order of the LOIs of the epoxy resins was $(\mathrm{B})=(\mathrm{F})>(\mathrm{A})>(\mathrm{E})>(\mathrm{C})>(\mathrm{D})$, when cured using $4,4^{\prime}$-methylenedianiline (DDM). Degradation proceeds in a single stage in an atmosphere of nitrogen and in two stages in air. At $800{ }^{\circ} \mathrm{C}$, the epoxy polymer (D) has the highest char yield of all the epoxy resins.
\end{abstract}

(C) 2004 Elsevier Ltd. All rights reserved.

Keywords: Glass transition temperature $\left(T_{\mathrm{g}}\right)$; Differential scanning calorimetry (DSC); Thermogravimetric analysis (TGA); Limited oxygen index (LOI) tester

\section{Introduction}

Most flame-retardant materials contain halogens. Toxic, corrosive gases and large amounts of smoke are produced when they burn [1]. For environmental reasons, flame-retardant materials that do not contain halogens, such as phosphorus-containing materials, have been developed [2]. Basic facts concerning the flame resistance of polymeric materials have been published [3]. Aromatic rigid rod moiety epoxy polymers have been studied because of their thermal stability [4]. The degree of flammability of a polymeric material can be predicted from its chemical structure. In other words, there must be

\footnotetext{
* Corresponding author. Fax: +886-2-27317117.

E-mail address: f10421@ntut.edu.tw (Y.-F. Duann).
}

some kind of relationship between thermal stability of aromatic epoxy polymers and their structure.

Naphthalene and phenyl rings have planar structures and can thus be easily packed. Such 'hard' structures increase the curing temperature and $T_{\mathrm{g}}$ of bismaleimide $[5,6]$. Naphthalene and phenyl tri-functional epoxy resins [7] have been reported to yield a high $T_{\mathrm{g}}$ and a high thermal stability $[8,9]$. The $T_{\mathrm{g}}$ increases as the functionality (di-, tetra-, pentafunctionality) of the epoxy increases. The phenyl-based epoxy resins [10-13] also exhibit the same phenomenon but their $T_{\mathrm{g}}$ was lower than those of naphthalene-based epoxy resins.

The combustion and burning of a polymer is a very complex process. In general, thermogravimetric analysis (TGA), the oxygen index (OI) and a cone calorimeter are used to determine factors, which influence the thermal stability of a polymer. In this study, naphthalene- and 
phenyl-based epoxies were synthesized and completely cured with DDM. Thermogravimetric analysis (TGA), differential scanning calorimetry (DSC) and limiting oxygen index (LOI) tester were used to examine the thermal stability of these systems. The synthetic procedures of epoxy monomer $(\mathbf{A}-\mathbf{F})$ are outlined in Fig. 1. The structures of epoxy monomers $(\mathbf{A}-\mathbf{F})$ are shown in Table 1. The curing processes of epoxy monomers $(\mathbf{A}-\mathbf{F})$ cured with 4,4'-methylenedianiline (DDM) are presented in Fig. 2.

\section{Experimental}

1,5-Dihydroxynaphthalene and 4,4'-dihydroxybiphenyl were purchased from Tokyo Chemical Co. 2,7-Dihydroxynaphthalene, 2,2'-dihydroxybiphenyl, 4,4'-methylenedianiline (DDM), sulfanilamide (SAA) and 1,1'-bi-2-naphthol were obtained from ACROS Chemical Co. 4-Aminophenol and 4-hydroxybenzaldehyde were purchased from Riedel-de Haën Chemical Co. Tetramethyl biphenol epoxy (TMBP) was supplied by Shell Chemical Co. with a trade name of RSS1407 and an epoxy equivalent of 185 . The bisphenol A epoxy (DGEBA) was supplied by Dow Chemical Co. with a trade name of DER 331 and an epoxy equivalent of 186. Solvents and reagents were reagent-grade and used as received without further purification.

The thermal decomposition of epoxy resins were thermogravimetrically analysed using TGA, Du Pont 951 instrument coupled to a Thermal Analyst 2000 in flowing $(60 \mathrm{ml} / \mathrm{min})$ air or nitrogen. Samples of $9-12 \mathrm{mg}$ were used. Four different heating rates were examined: $2.5,5,10$ and $15^{\circ} \mathrm{C} / \mathrm{min}$ from $50{ }^{\circ} \mathrm{C}$ to $800{ }^{\circ} \mathrm{C}$.

Diol + epichlorohydrin $\longrightarrow$ epoxy resin monomer $(\mathbf{A}, \mathbf{B}, \mathbf{C}, \mathbf{E}, \mathbf{F})$

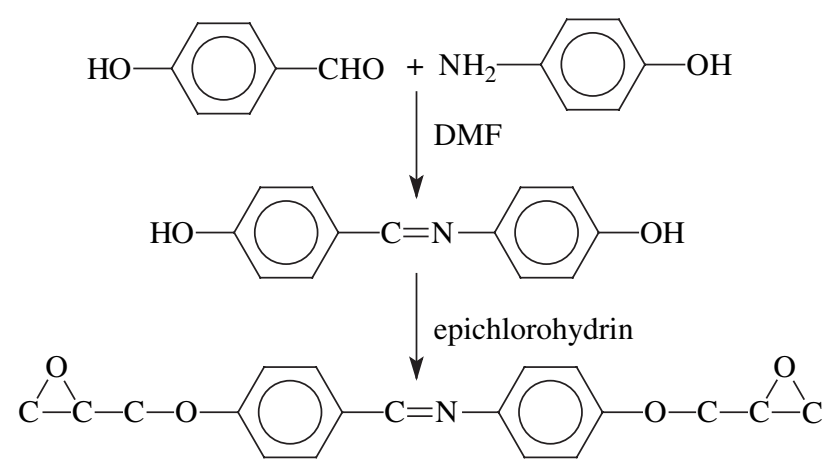

epoxy resin monomer (D)

Fig. 1. The synthesis procedure of epoxy monomer $(\mathbf{A}-\mathbf{F})$.
The glass transition temperature was measured by a differential scanning calorimeter (Du Pont DSC 10). Dry nitrogen was used as a purge gas. Samples of approximately $5 \mathrm{mg}$ were enclosed in aluminium DSC capsules. Dynamic heating experiments were performed with a nitrogen flow of $60 \mathrm{ml} / \mathrm{min}$, and five different heating rates were considered: $2.5,5,10,15$ and $20^{\circ} \mathrm{C} /$ $\min$ from $30{ }^{\circ} \mathrm{C}$ to $300{ }^{\circ} \mathrm{C}$.

The LOI was determined with a Suga ON-1 instrument following the ASTM D 2863-95 procedure.

${ }^{1} \mathrm{H}$ NMR spectra were measured using a BRUKER AV-300 MHz FT-NMR spectrometer. IR spectra were recorded on a Perkin-Elmer (SPECTRUM 2000) FT-IR spectrometer.

\section{Synthesis}

\subsection{1,5-Di(2,3-epoxypropoxy)naphthalene (A)}

Compounds A, B, C, E and $\mathbf{F}$ were prepared according to the following procedure. A mixture of $20 \mathrm{~g}$ of 1,5-dihydroxynaphthalene, $195 \mathrm{ml}$ of epichlorohydrin, and a trace amount of benzyl trimethyl ammonium chloride (BTEA) in a $500 \mathrm{ml}$ three-neck round-bottom flask fitted with a condenser was refluxed until all the reactants were dissolved. The temperature of the mixture was maintained at $60{ }^{\circ} \mathrm{C}$, then $40 \%$ sodium hydroxide aqueous solution was added slowly over a period of $3 \mathrm{~h}$. The reaction mixture was stirred at room temperature for another $2 \mathrm{~h}$. The unreacted epichlorohydrin was separated by a vacuum system. The solid mixture was washed with $20 \mathrm{ml}$ of ether and $100 \mathrm{ml}$ of water. The solid was recrystallised using a methanol ether mixture.

\subsection{4,4'-Bis (2,3-epoxypropoxy) benzylideneaniline $(\boldsymbol{D})$}

A mixture of $24.4 \mathrm{~g}$ of 4-aminophenol, $21.8 \mathrm{~g}$ of 4hydroxybenzaldehyde and $180 \mathrm{ml}$ of DMF was placed in a $500 \mathrm{ml}$ three-neck round-bottom flask fitted with a condenser under nitrogen. The reaction mixture was stirred for $30 \mathrm{~min}$ and then the temperature increased to $65^{\circ} \mathrm{C}$ for another $8 \mathrm{~h}$. The reaction temperature was reduced and DMF was separated using a vacuum system; then $270 \mathrm{ml}$ of epichlorohydrin, and a trace amount of benzyl trimethyl ammonium chloride (BTEA) were added. The temperature of the mixture was maintained at $60{ }^{\circ} \mathrm{C}$, then $40 \%$ sodium hydroxide aqueous solution was added slowly over a period of $3 \mathrm{~h}$. The reaction mixture was stirred at $60{ }^{\circ} \mathrm{C}$ overnight. The unreacted epichlorohydrin was separated by a vacuum system. The solid mixture was washed with $20 \mathrm{ml}$ of ether and $100 \mathrm{ml}$ of water. The solid was recrystallised using methanol and ether mixture. 
Table 1

Names and structures of epoxy monomers $(\mathbf{A}-\mathbf{F})$

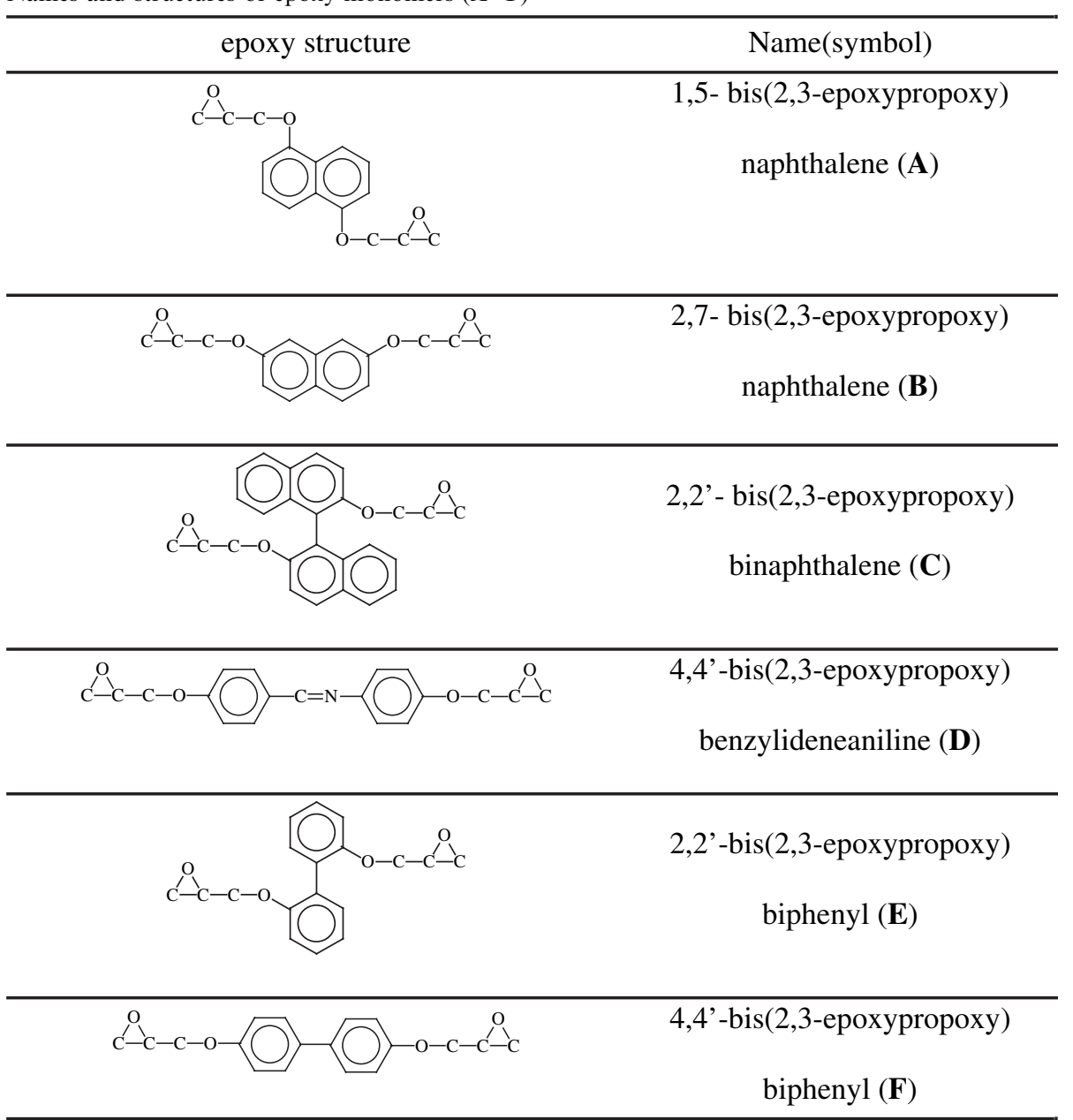

\subsection{Curing}

The curing conditions of epoxy monomers $(\mathbf{A}-\mathbf{F})$ using the curing agent (DDM) were checked by the results of differential scanning calorimetry (DSC), over the temperature range $30-300{ }^{\circ} \mathrm{C}$, at a heating rate of $10{ }^{\circ} \mathrm{C} / \mathrm{min}$. The epoxy monomer was used in the powder state, except that monomer $(\mathbf{E})$ was a liquid.

\section{Results and discussion}

\subsection{Differential scanning calorimetry (DSC)}

In this study, polymers $(\mathbf{A}-\mathbf{C})$ are naphthalene-based epoxy polymers and $(\mathbf{D}-\mathbf{F})$ are phenyl-based polymers. Table 2 presents the glass transition temperatures $\left(T_{\mathrm{g}}\right)$ of the cured epoxy polymers.

Polymer $(\mathbf{C})\left(T_{\mathrm{g}}=204{ }^{\circ} \mathrm{C}\right)$ has higher $T_{\mathrm{g}}$ than that of polymer $(\mathbf{E})\left(T_{\mathrm{g}}=128{ }^{\circ} \mathrm{C}\right)$. Epoxy polymer $(\mathbf{C})$ is naphthalene-based and polymer $(\mathbf{E})$ is phenyl-based.
$T_{\mathrm{g}}$ of polymer $(\mathbf{A})\left(T_{\mathrm{g}}=213^{\circ} \mathrm{C}\right)$ is the highest of all the studied polymers. The naphthalene-based epoxy resin in polymer (A) (1,5-di-substituted) has a more symmetric structure than that in polymer (B) (2,7-di-substituted) of which $T_{\mathrm{g}}$ is $175^{\circ} \mathrm{C}$. Polymer $(\mathbf{F})\left(T_{\mathrm{g}}=177^{\circ} \mathrm{C}\right)$ is also more symmetrical and has a higher $T_{\mathrm{g}}$ than polymer $(\mathbf{E})$ $\left(T_{\mathrm{g}}=128^{\circ} \mathrm{C}\right)$. It seems that the more symmetric structure causes the higher $T_{\mathrm{g}}$. The other reason for the lower $T_{\mathrm{g}}$ of polymer $(\mathbf{E})$ than that of polymer $(\mathbf{F})$ could be the steric hindrance. Polymer (E) is strongly hindered in comparison with polymer $(\mathbf{F})$. They are biphenyl-based structures where polymer (E) is 2,2' -disubstituted and polymer (F) is $4,4^{\prime}$-di-substituted; the biphenyl is more twisted in structure $(\mathbf{E})$.

\subsection{Thermogravimetric analysis (TGA)}

The TGA measurements have been done under atmospheres of nitrogen and air. Figs. 3 and 4 show the TGA curves for epoxy polymers in nitrogen and air, respectively, at a $10{ }^{\circ} \mathrm{C} / \mathrm{min}$ heating rate. 
<smiles>C(O[Al]OCC1CO1)C1CO1</smiles>

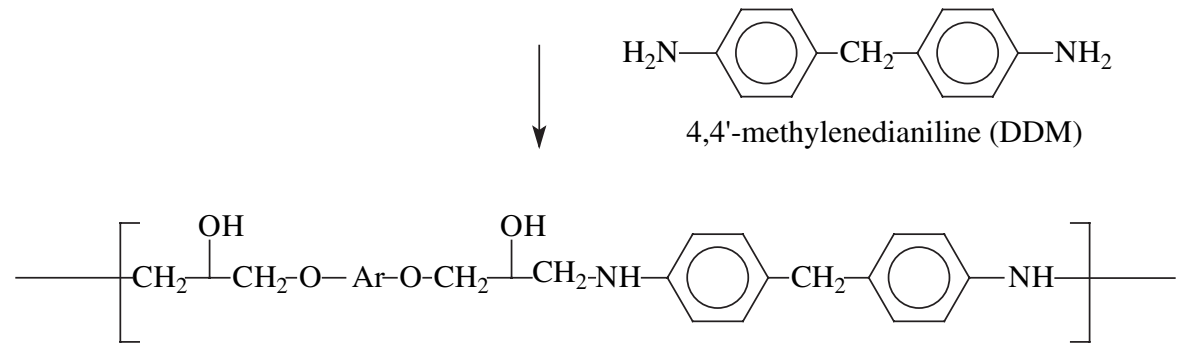

Fig. 2. The curing reaction of epoxy polymer $(\mathbf{A}-\mathbf{F})$.

Table 3 presents the results of thermogravimetric analysis (TGA) and weight loss during degradation in an atmosphere of nitrogen or air.

From 350 to $450{ }^{\circ} \mathrm{C}$, epoxy polymers $(\mathbf{B}),(\mathbf{C})$ and $(\mathbf{E})$ degrade more quickly than the others. At $800{ }^{\circ} \mathrm{C}$, epoxy polymer (D) has a higher char yield than all the other polymers. The degradation is more complex for all epoxy polymers when TGA is measured in an atmosphere of air. Degradation is a single-stage process in an atmosphere of nitrogen and a two-stage process in air. Therefore, the degradation mechanism is different under each degradation condition. The residual weight in air $(1-3 \%)$ is lower than that in nitrogen $(12-48 \%)$ at $800{ }^{\circ} \mathrm{C}$.

\subsection{Limiting oxygen index (LOI)}

The relative flammability of epoxy resins $(\mathbf{A})-(\mathbf{F})$ was examined using the limiting oxygen index (LOI). Table 4 lists the results. The decreasing order of the LOIs of epoxy resins is $(\mathrm{B})=(\mathrm{F})>(\mathrm{A})>(\mathrm{E})>(\mathrm{C})>(\mathrm{D})$. The polymer (D) is the easiest to burn.

Another experiment also yields the same result. Two monomers, 4,4'-bis(2,3-epoxypropoxy)benzylideneaniline and 4,4'-bis(2,3-epoxypropoxy)biphenyl, are cured using curing agent sulfanilamide (SAA), forming the polymers $(\mathbf{G})$ and $(\mathbf{H})$, respectively. Fig. 5 depicts the structures of the cured polymers.

Table 5 presents the thermogravimetric analysis (TGA) in an atmosphere of nitrogen or air and the LOIs of polymers $(\mathbf{G})$ and $(\mathbf{H})$.

Polymers (D) and (G) used the same starting monomer but different curing agents. The char yield of

Table 2

Glass transition temperatures $\left(T_{\mathrm{g}}\right)$ of epoxy polymers $(\mathbf{A}-\mathbf{F})$

\begin{tabular}{llll}
\hline Polymer & $T_{\mathrm{g}}\left({ }^{\circ} \mathrm{C}\right)$ & Polymer & $T_{\mathrm{g}}\left({ }^{\circ} \mathrm{C}\right)$ \\
\hline $\mathbf{A}$ & 213 & $\mathbf{D}$ & 200 \\
$\mathbf{B}$ & 175 & $\mathbf{E}$ & 128 \\
$\mathbf{C}$ & 204 & $\mathbf{F}$ & 177 \\
\hline
\end{tabular}

polymer $(\mathbf{G})$ is higher than that of polymer $(\mathbf{H})$. The LOIs of polymer $(\mathbf{G})$ and polymer $(\mathbf{H})$ are 26.5 and 31.5 , respectively. Polymer (G) is more flammable than polymer $(\mathbf{H})$. The LOI of polymer $(\mathbf{D})$ is lower than that of polymer $(\mathbf{G})$ and that of polymer $(\mathbf{F})$ is lower than that of polymer $(\mathbf{H})$. The major difference between the structures of (A) and (B) is the position of the substituent. The position of the substituent of epoxy

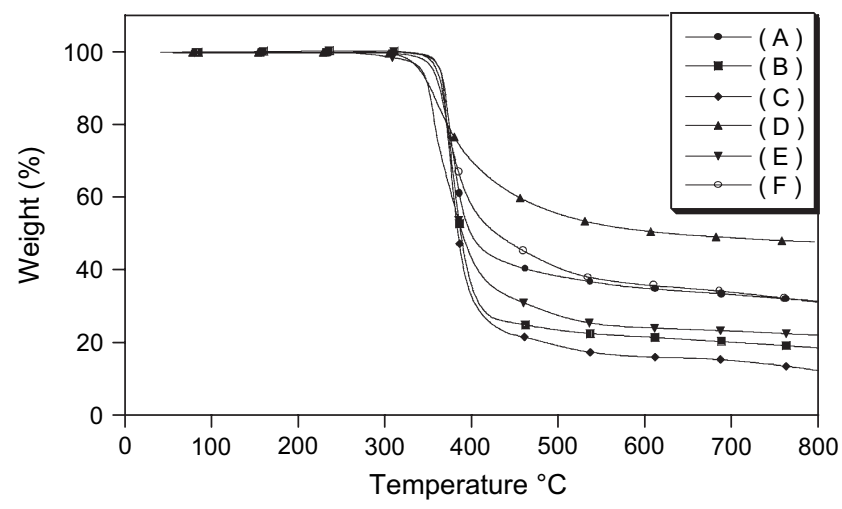

Fig. 3. The TGA curves of epoxy polymers in nitrogen at $10{ }^{\circ} \mathrm{C} / \mathrm{min}$ heating rate.

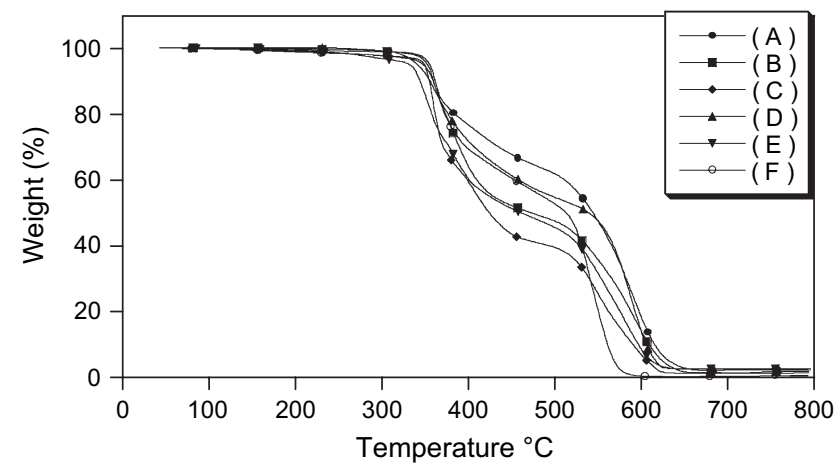

Fig. 4. The TGA curves of epoxy polymers in air at $10{ }^{\circ} \mathrm{C} / \mathrm{min}$ heating rate. 
Table 3

Results of thermal degradation of epoxy resins $(\mathbf{A}-\mathbf{F})$ cured with DDM measured by TGA in nitrogen and air atmosphere at $10{ }^{\circ} \mathrm{C} / \mathrm{min}$ heating rate

\begin{tabular}{|c|c|c|c|c|c|c|c|}
\hline & \multirow[t]{2}{*}{ Epoxy } & \multirow{2}{*}{$\begin{array}{l}5 \% \text { Weight } \\
\text { loss } T\left({ }^{\circ} \mathrm{C}\right)\end{array}$} & \multirow{2}{*}{\multicolumn{2}{|c|}{$\begin{array}{c}\text { Maximum } \\
\text { break } T\left({ }^{\circ} \mathrm{C}\right)\end{array}$}} & \multicolumn{3}{|c|}{ Residual weight (\%) } \\
\hline & & & & & $350{ }^{\circ} \mathrm{C}$ & $450{ }^{\circ} \mathrm{C}$ & $800{ }^{\circ} \mathrm{C}$ \\
\hline \multirow[t]{6}{*}{$\mathrm{N}_{2}$} & $\mathbf{A}$ & 364 & 37 & 74 & 99 & 41 & 32 \\
\hline & B & 360 & 37 & 77 & 98 & 26 & 19 \\
\hline & C & 364 & 37 & 72 & 99 & 22 & 12 \\
\hline & D & 341 & 36 & 60 & 91 & 61 & 48 \\
\hline & $\mathbf{E}$ & 343 & 35 & 55 & 90 & 32 & 22 \\
\hline & $\mathbf{F}$ & 356 & 37 & 70 & 97 & 47 & 31 \\
\hline \multirow[t]{7}{*}{ Air } & & & Stage 1 & Stage 2 & & & \\
\hline & $\mathbf{A}$ & 356 & 362 & 591 & 97 & 68 & 3 \\
\hline & B & 353 & 359 & 591 & 96 & 52 & 2 \\
\hline & $\mathbf{C}$ & 352 & 360 & 548 & 96 & 44 & 2 \\
\hline & D & 342 & 362 & 588 & 93 & 62 & 3 \\
\hline & $\mathbf{E}$ & 333 & 351 & 590 & 87 & 52 & 2 \\
\hline & $\mathbf{F}$ & 348 & 366 & 541 & 95 & 61 & 2 \\
\hline
\end{tabular}

Table 4

Limiting oxygen index (LOI) of epoxy polymer $(\mathbf{A}-\mathbf{F})$

\begin{tabular}{llll}
\hline Polymer & LOI & Polymer & LOI \\
\hline $\mathbf{A}$ & 29.5 & $\mathbf{D}$ & 26.0 \\
$\mathbf{B}$ & 30.0 & $\mathbf{E}$ & 28.5 \\
$\mathbf{C}$ & 27.0 & $\mathbf{F}$ & 30.0 \\
\hline
\end{tabular}

monomers (A) and (B) are 1,5- and 2,7-, respectively. They have almost the same LOI. In Table 4, the LOI of polymer (B) is slightly higher than that of polymer (A). Therefore, the position of the substituent does not affect LOI in this case.

\subsection{Activation energy $\left(\mathrm{E}_{a}\right)$}

The activation energy for degradation of these epoxy polymers was calculated by Ozawa's method [14]. Four different heating rates were applied-2.5, 5, 10 and $15^{\circ} \mathrm{C} / \mathrm{min}$-from 50 to $800{ }^{\circ} \mathrm{C} / \mathrm{min}$. Tables 6 and 7 present the activation energies of degradation calculated by Ozawa's methods and measured in nitrogen and air, respectively.

The order of the average activation energies of degradation follows $(\mathrm{D})>(\mathrm{A})>(\mathrm{F})>(\mathrm{B})>(\mathrm{C})>(\mathrm{E})$ in nitrogen. In Table 6 , the order of average activation energies of degradation of stage 1 is $(\mathrm{D})>(\mathrm{A})>(\mathrm{F})>$ $(\mathrm{C})>(\mathrm{B})>(\mathrm{E})$. Table 7 reveals small difference in the average activation energies of degradation between stage 1 and stage 2 . The epoxy polymer (D) has a long conjugated double bond in which two phenyl groups are connected by a $\mathrm{C}=\mathrm{N}$ double bond, such that the structure is more stable than the other polymers.

\section{Conclusions}

The six epoxy resins can be divided into two different groups. One is naphthalene-based and the other is of the phenyl type. The colour of the epoxy polymer, formed by curing epoxy monomers $(\mathbf{A}-\mathbf{F})$ with DDM, is deep brown. In some cases, curing is performed under reduced pressure to prevent air bubbles from forming. Based on the results in this study, we concluded the following.<smiles>C(O[Al]OCC1CO1)[Al]OCC1CO1</smiles>

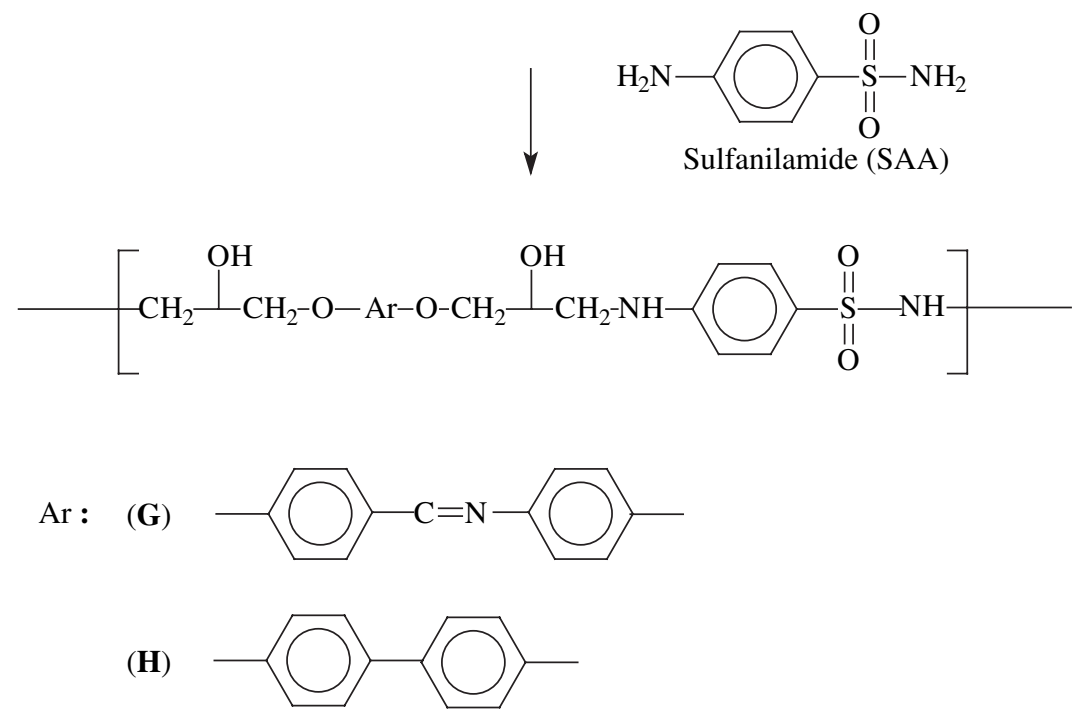

Fig. 5. The curing reaction of epoxy monomer $(\mathbf{G}-\mathbf{H})$. 
Table 5

Results of thermal degradation and LOI of epoxy resins $(\mathbf{G}-\mathbf{H})$ cured with SAA measured by $\mathrm{TGA}$ in nitrogen or air atmosphere at $10{ }^{\circ} \mathrm{C} /$ min heating rate

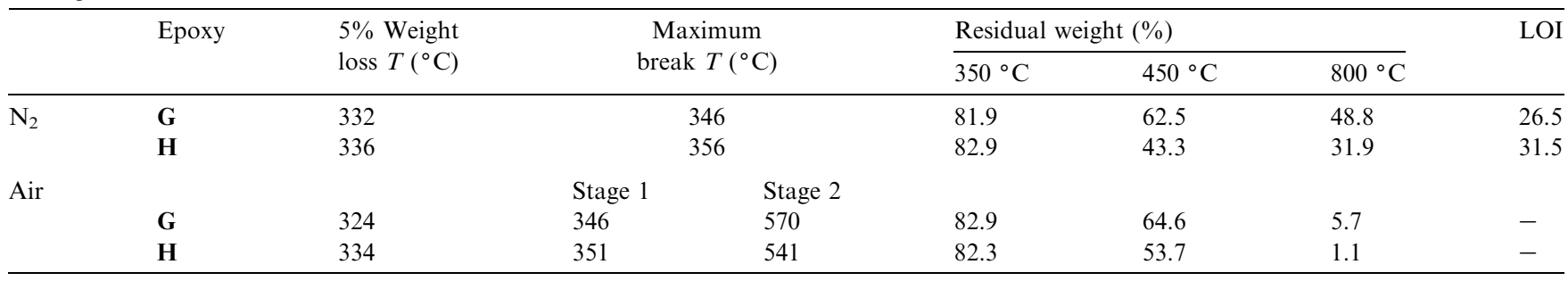

1. Degradation is more complex for all epoxy polymers when TGA is measured in an atmosphere of air. Degradation proceeds in a single stage in nitrogen and in two stages in air.

2. At $800^{\circ} \mathrm{C}$, epoxy polymer (D) that comes from 4,4' -bis(2,3-epoxypropoxy)benzylideneaniline cured with DDM gives the highest char yield of all the epoxy resins.

Table 6

The degradation energy $(\mathrm{kJ} / \mathrm{mol})$ calculated with Ozawa method in nitrogen atmosphere

\begin{tabular}{lllllll}
\hline $\begin{array}{l}\text { Fractional weight } \\
\text { loss }(\%)\end{array}$ & \multicolumn{7}{l}{ Activation energy, $E(\mathrm{~kJ} / \mathrm{mol})^{\mathrm{a}}$} \\
\cline { 2 - 7 } & A & B & C & D & E & F \\
\hline 5 & 174 & 126 & 149 & 193 & 113 & 137 \\
10 & 185 & 130 & 150 & 204 & 134 & 150 \\
20 & 184 & 139 & 150 & 232 & 139 & 167 \\
30 & 181 & 153 & 149 & & 149 & \\
40 & 187 & 160 & 148 & & 165 & \\
50 & & 169 & 148 & & & \\
60 & & 191 & 150 & & & \\
Average $E$ & 185 & 153 & 150 & 208 & 139 & 160 \\
\hline
\end{tabular}

${ }^{\text {a }}$ The $E_{\mathrm{a}}$ value was calculated using four different temperatures in each fractional weight loss. The $R$-value was in the range $0.988-0.953$, and the S.D. was $0.010-0.007$.

Table 7

The degradation energy $(\mathrm{kJ} / \mathrm{mol})$ calculated with Ozawa method in air atmosphere

\begin{tabular}{lllllll}
\hline $\begin{array}{l}\text { Fractional weight } \\
\text { loss }(\%)\end{array}$ & \multicolumn{7}{c}{ Activation energy, $E(\mathrm{~kJ} / \mathrm{mol})^{\mathrm{a}}$} \\
\cline { 2 - 7 } & A & B & C & D & E & F \\
\hline 5 & 196 & 137 & 178 & 188 & & 141 \\
10 & 198 & 156 & 175 & 236 & 138 & 171 \\
20 & & 192 & 192 & 317 & 167 & 272 \\
Average $E_{1}$ & 212 & 168 & 184 & 238 & 156 & 209 \\
50 & 136 & & & 193 & & 152 \\
60 & 118 & 186 & & 150 & 204 & 140 \\
70 & 108 & 142 & & 137 & 140 & 137 \\
80 & 101 & 124 & 142 & 126 & 120 & 123 \\
90 & 95 & & 116 & 118 & 117 & 121 \\
Average $E_{2}$ & 110 & 142 & 140 & 141 & 138 & 133 \\
\hline
\end{tabular}

${ }^{\text {a }}$ The $E_{\mathrm{a}}$ value was calculated using four different temperatures in each fractional weight loss. The $R$-value was in the range $0.987-0.955$, and the S.D. was $0.01-0.006$.
3. The degradation activation energy of these epoxy resins was determined by Ozawa's method. Epoxy polymer (D) has the greatest degradation activation energy of all the epoxy resins considered here, regardless of whether they are in nitrogen or air.

4. The order of the LOIs of the epoxy resins studied in this article is $(\mathrm{B})=(\mathrm{F})>(\mathrm{A})>(\mathrm{E})>(\mathrm{C})>(\mathrm{D})$, when cured using 4,4' -methylenedianiline (DDM).

5. Naphthalene-based epoxy resins (A) and (B) have almost the same LOIs, indicating that the position of the substituent only weakly affects the LOI.

6. Epoxy resin (D) has the lowest LOI. The same trend is followed when this monomer was cured using sulfanilamide (SAA).

\section{Acknowledgements}

The authors would like to thank the National Science Council of the Republic of China for financially supporting this research.

\section{References}

[1] Buckingham MR, Lindsay AJ, Stevenson DE, Muller G, Morel E, Costes B, et al. Polym Degrad Stab 1996;54:311-5.

[2] Liu YL, Hsiue GH, Chiu YS, Jeng RJ. J Appl Polym Sci 1996;61: 1789-96.

[3] Su W-FA. J Polym Sci Part A Polym Chem 1993;31:3251-6.

[4] Carfagna C, Amendola E, Giamberini M, Filippov A, Bauer RS. Liq Cryst 1993;13:571-84.

[5] Wang CS, Hwang HJ. J Polym Sci Part A Polym Chem 1996;34: $1493-500$

[6] Wang CS, Leu TS, Hsu KR. Polymer 1998;39:2921-7.

[7] Wang CS, Lee MC. J Appl Polym Sci 1998;70:1907-21.

[8] Wang CS, Lee MC. Polym Bull 1998;40:623-30.

[9] Wang CS, Lee MC. Polymer 2000;41:3631-8.

[10] Mikroyannidis JA. J Appl Polym Sci 1990;41:2613-24.

[11] Ochi M, Shimizu Y, Nakanishi Y, Murata Y. J Polym Sci Part B Polym Phys 1997;35:397-405.

[12] Su W-FA, Chen KC, Tseng SY. J Appl Polym Sci 2000;78: $446-51$.

[13] Lee JY, Jang J, Hwang SS, Hong SM, Kim KU. Polymer 1998;39: 6121-6.

[14] Ozawa T. Bull Chem Soc Jpn 1965;38:1881-6. 